\title{
Las muestras curatoriales de Aguascalientes 2015
}

\section{Enrique Mijares}

Con un balance cada vez más exiguo en cuanto a la presencia de los estados, tuvo lugar en Aguascalientes la 36 Muestra Nacional de Teatro, un evento cuyo espíritu original consistía en mostrar el teatro que se estaba haciendo en el interior del país, es decir, en las treinta y tantas entidades federativas que conforman la república y al cual asistirían en calidad de invitados cuando mucho tres grupos de la capital.

Doce únicamente fueron en esta ocasión las delegaciones del interior que acudieron al muestreo. Jalisco, Yucatán y Aguascalientes con tres obras cada una. Baja California, Nuevo León y Veracruz con dos. Y con un espectáculo por entidad: Chihuahua, Guanajuato, Guerrero, Querétaro, Sonora y Oaxaca. En tanto que de la Ciudad de México participaron doce, bueno, trece, si contamos que La Compañía Nacional, con patrocinio de Campeche, incluyó dos - El galán de ultramar y La amante - de las seis que conforman el ciclo Los grandes muertos montadas bajo la dirección de Pepe Caballero y que a su vez forman parte de la serie aun más extensa de la creadora emérita campechana Luisa Josefina Hernández.

En síntesis, doce estados (la tercera parte de la geografía política nacional), si bien con veintiuna obras; versus las doce obras representantes del otrora denominado Distrito Federal. Es decir, 33 lugares que muy bien podrían haber sido ocupados por las treinta y tantas entidades federativas que José Solé soñaba con aglutinar en el propósito ecuménico que dio origen a su iniciativa.

Sin embargo, la distribución de los espacios no es lo único preocupante; también el renovado fervor posmoderno con que se intenta etiquetar la participación desde lineamientos llamados curatoriales, una suerte de baremo aplicado a la república teatral, desde el cual se pretenden 'ponderar' los méritos de los grupos artísticos, pero muy en particular, sospechamos, evidenciar la solvencia de las producciones, como quien dice, una 'muestra' para 'mostrarla' 
al patrón gobierno, prueba fehaciente para establecer meridianamente 'qué tanto estamos haciendo las instituciones de cultura por el arte escénico que se practica en el país.' Esto es, en conclusión, una 'muestra' no enfocada a la comunidad que practica y consume teatro, sino de cara tanto a la distribución presupuestal como a justificar la existencia y los objetivos de las instancias destinadas a coordinar dichas actividades.

Constancia irrefutable de lo que priva en el ánimo de los teatreros es la referencia constante al financiamiento que en su gran mayoría los creadores comentaron en las sesiones diarias denominadas "Encuentro de reflexión e intercambio, un espacio para compartir experiencias y saberes relacionados con la teatralidad". Antes que hablar de sus ideas, procedimientos, tendencias y acciones estéticas, o de la formación y la relación con los diferentes públicos, los participantes hicieron hincapié en el aspecto financiero de sus proyectos, fincando su atención en los modelos de producción, las redes y estrategias utilizadas para allegarse recursos, acceder a presupuestos, aunque para obtenerlos y aplicarlos a fines artísticos debieron recurrir casi siempre a convocatorias relacionadas con programas sociales o del sector salud que les exigían capacitación en habilidades no propiamente teatrales, cabe decir, 'actuando o representando' ser activistas interesados en cometidos comunitarios.

Que toda taxonomía curatorial es arbitraria resulta evidente la mayoría de las veces, en especial cuando se trata de un fenómeno cuya naturaleza es de suya proteica y acumula recursos de disciplinas artísticas que, por definición, se nutren de diversas pertenencias, saberes, experiencias y creatividades. Ello se puso de manifiesto cuando casi todos los participantes se mostraron inconformes con ser catalogados, por ejemplo, como teatro universitario o comunitario o fenómenos performáticos o de teatralidad lateral. Incluso hubo casos en que obras clasificadas como de grupos independientes acudían subvencionadas por alguna institución. Etcétera. Toda una diversidad propia del quehacer teatral, multifactorial de suyo, al que se pretende encasillar por una sola de sus cualidades, siendo que desde sus orígenes el teatro es un fenómeno de múltiples vertientes, en el cual confluyen recursos tomados de otras tantas disciplinas así literarias como tecnológicas.

Ileana Diéguez lo expresó con nitidez al moderar el primer Encuentro de reflexión: "ese poder enunciativo es sobre todo un poder vinculante que cita "convenciones de autoridad" como declarar "esto es teatro", "esto es performance" o "esto es escena expandida". El investigador del CITRU, Israel Franco, moderador del segundo Encuentro, para refrendar que las categorías curatoriales son cajones con propósitos estancos y arbitrarios, 
recordó que aunque en esta ocasión existiera una línea curatorial específica, 6 Teatro Comunitario, en la que se incorpora por derecho propio La Maroma mixteca, propuestas con ese perfil han sido programadas en otras muestras nacionales. Puso de ejemplo al grupo Maak Mayaab (Gente que no abunda en el mundo), de Yucatán, con la obra hablada en maya Ma'tinaa 'ti Kech (No te entiendo), dirigida por Juan de la Rosa, en coautoría con Socorro Loeza, que participó en la MNT Juárez 2008, y las luminosas ocasiones que Teatro de Tehuantepec de Marco Pétriz ha participado en el evento anual.

En la práctica, como suele ocurrir en todas las Muestras, haciendo caso omiso de la categorización curatorial, no faltó quien, erigido en teatrero/ espectador/crítico cuestionara: ¿A quién demonios se le ocurrió seleccionar tal o cual obra? O bien que refiriéndose a tal o cual otra dijera "Eso sí es buen teatro", tal vez siguiendo la definición de teatro de calidad que acuñara José Luis García Barrientos en el reciente FIT de Cádiz: "aquel del que todos salimos diciendo que nos gustó".

No daré ejemplos de lo uno ni de lo otro. En cambio comentaré que hubo obras: Duran66o. Objetos para actualizar un acontecimiento histórico dirigida por Jorge Vargas; Todos somos Calibán de Guanajuato y dirección de Sara Pinedo; Historia(s) del teatro en México con la excelente actuación de Alejandro Guerrero; Del manantial del corazón con la impecable factura integral de Conchi León. Todas fueron capaces de despertar el interés ideológico de los espectadores y en algunos casos no sólo invitaron a la reflexión sino que motivaron al público a prolongar la experiencia hasta apropiarse, reinterpretar y recrear las propuestas escénicas desde su propio contexto vital.

Vaya un par de comentarios personales al respecto.

Duran66o. Objetos para actualizar un acontecimiento histórico reactivó el imaginario que suscitan en mi memoria las repercusiones expansivas de ilusión y desencanto que el fenómeno social irrepetible ha seguido teniendo en el ánimo de los durangueños a lo largo de casi medio siglo. Sin embargo - dado que no puedo confiar demasiado en mis testimonios personales como testigo en 1966, más la información que he venido recabando a través de un arduo proceso de investigación y que están contenidos en una novela, dos obras teatrales, un ensayo con premio estatal y varios artículos-, recurro sin escatimar espacio a la 'recepción desde fuera' que me proporciona la conversación con el ensayista argentino Andrés Gallina:

¿Cómo reconstruir un relato del pasado a partir de los restos, de los desechos, de las huellas? ¿Cómo nos hablan y qué nos dicen ahora la suma de relatos de un acontecimiento del pasado? ¿Qué dispositivos 
de presencia se pueden saquear para pensar formas de vínculo entre las teatralidades y las memorias? [...] La obra alumbra preguntas en torno a los modos de habitar la escena y de pensar vínculos entre las teatralidades y los dispositivos que construyen memoria. [...] el grupo no deja de preguntarse cómo, en la medida en que narran una historia, están invariablemente, ellos mismos, siendo narrados. [...] Hay una afirmación que vuelve a lo largo de la pieza como un eco: "iluminar un territorio como un relámpago en la noche". Los elementos formales toman también la forma de ese relámpago: momentos donde entra una luz y se va, pequeñas descargas con diferentes voltajes. [...] La obra, desde su fuerza visual, desde sus irradiaciones plásticas, plantea una potente lectura escénica sobre los modos de recordar, sobre la incompletud y la falta que sostiene toda instancia evocativa. Como dice Paolo Virno, somos historia no sólo por percibir el instante en que vivimos sino más bien por recordarlo mientras lo estamos viviendo.

Todos somos Calibán me hace intentar — sin ánimo comparativo de grado o de efectividad - una analogía así conceptual como perceptual, entre los recuerdos culinarios que los ancestros han dejado en la memoria de los actores de Cuando todos pensaban que habiamos desaparecido de Vaca 35 en el reciente FIT de Cádiz, y las confesiones descarnadas, en la MNT Aguascalientes 2015, de estas mujeres — mater admirabilis - procedentes de un pequeño poblado de Guanajuato, que se abren la blusa para mostrar el pecho desnudo tatuado con el nombre del hijo ausente, mientras quitan las espinas a los nopales que luego van a cocinar y a ofrecer a los asistentes a este acontecimiento convival. Concepciones de puesta en escena similares. Semejante impacto emocional. La única diferencia posible entre ambas estriba en la inversión pecuniaria utilizada y el sector socioeconómico —un abismal contraste entre lo rural y lo cosmopolita - a que pertenecen los intérpretes en cada caso.

En cuanto a Del manantial del corazón - título del que la propia León dice, "Es cursi, pero la obra es buena"- no tengo sino aplausos y reconocimientos para ese biodrama inefable, entrañable, ese cúmulo de vivencias y de memoria ancestral que es Conchi, una mestiza power que en esta ocasión habla de los ritos de la maternidad y del nacimiento que hay en el Mayab y que al finalizar la función, la dramaturga, directora y actriz relacionó de manera solidaria con la tragedia de fuego en la guardería ABC de Hermosillo, un hecho que permanece impune y al que el gobernador en turno, cuestionado al respecto por la opinión pública acerca de cómo podía conciliar el sueño, 
cargado de soberbia y estulticia, simplemente respondió, "Yo duermo como un bebé".

De nuevo - por considerar que mi voz puede estar viciada de parcialidad por ser de casa, del interior del país para ser exactos, y haber formado parte alguna vez de la dirección artística de la Muestra - cedo la palabra a Andrés Gallina, cuya mirada 'externa' y la agudeza investigadora que le distingue autorizan la ecuanimidad de su análisis:

Aspiracional no estaba nada bien. Muy tediosa, predecible, con un humor muy interno, y con un dispositivo que se agotaba rápidamente. El público se durmió (me incluyo ahí). [...] El síndrome Duchamp era atractiva, había algo interesante en el diseño escénico (adaptado para este montaje), y el actor se defendía con recursos. Una lectura escénica sobre los inmigrantes mexicanos en Estados Unidos, con un cruce de Stand Up, biodrama y teatro de objetos. [...] Algo de un tal Shakespeare estaba muy bien actuada. Dialoga con algo del teatro que hace Rodrigo García. Por momentos, caía en una zona un tanto didáctica (glosando argumentos de las obras de Shakespeare), pero eso puede ser comprensible dado que entiendo está destinada a un público juvenil y familiar. [...] El cierre de La Maroma fue extraño. Por un lado se entiende el intento de recuperación y visibilidad de una teatralidad marginal; por el otro, es un tipo de espectáculo que reproduce gestos patriarcales, formas de machismo y otros modos reaccionarios. Me resultó complejo, por ajeno, pensar ese fenómeno.

En resumen: Una Muestra Nacional de Teatro más y las estrategias de insaculación programática se siguen barajando sin que al parecer consigan dar en el clavo, a despecho de las expectativas curatoriales que se han invertido esta vez en ello.

Sistema Nacional de Creadores de Arte

Universidad Juárez de Durango - México 